\title{
ASSESSMENT OF AN INNOVATIVE GROUP-BASED LEARNING TECHNOLOGY TO IMPROVE STUDENTS' PERFORMANCE
}

\author{
Izharul Haq ${ }^{1}$, Masood Ahmed ${ }^{2 \star}$ and Rubina $\mathrm{Haq}^{3}$ \\ ${ }^{1}$ Prof. Dr., Prince Mohammad Bin Fahd University, Saudi Arabia,ihaq@pmu.edu.sa \\ ${ }^{2}$ Assist. Prof. Mr., SZABIST, Karachi, Pakistan, masood@szabist.edu.pk \\ ${ }^{3}$ Mrs. International Islamic University, Pakistan, rubinahaq54@gmail.com \\ ${ }^{*}$ Corresponding Author
}

\begin{abstract}
Group-Based Learning (GBL) is a well-established and widely-used collaborative student-centric pedagogy in education. It provides improved learning, better classroom participation and enjoyable learning experience for students. Through GBL, students interact and learn from each other under the supervision of a teacher. Students are usually given a task to work on whilst the teacher goes around supporting and assessing them. Unfortunately, there exist several drawbacks of GBL: tracking individual student learning progress is extremely difficult; student grouping is usually done in an arbitrary manner; typically, group assessment marks are noted manually by the instructor; this results untimely and delayed feedback to students about their performance. Currently, all software applications are unable to solve these issues. Here we report on an innovative technology-based app (Group Based Learning or GBL) that greatly improves student learning and reduces teachers' workload by eliminating hours of work on analyzing student data, reporting and providing timely feedback to students. The GBL app is based on a recently introduced ROFSET (Real-time Objective Feedback System for Effective Teaching) Framework. This App allows both the teacher and students to capture key data on all important 21 st century skills within group learning. The analysis of the data is done automatically in real-time and is available for students and teachers. Our results show that using the GBL app, the students became much more responsive to learning. Also it allows the teacher to identify and support students who need more help (differentiated learning). In this work we present our findings on tracking students' skills in the following areas: Social, Communication, Analytics, Leadership and Effort (SCALE) for an introductory Physics class.
\end{abstract}

Keywords: Pedagogy, Group Based Learning, Technology, Software, ROFSET

\section{INTRODUCTION}

The use of technology to improve student learning is becoming an increasing phenomenon in education. Through technology education has become more interactive. (Raja \& Nagasubramani, 2018). There are many examples of the use of technology in education from distance learning through online courses to integrated learning where the division between theory and practice becomes narrow. Further to assess the student learning in the context of different pedagogies is also on rise. The study deals with application of ROFSET (Real-time Objective Feedback System for Effective Teaching framework in Group-BasedLearning.

\section{LITERATURE REVIEW}

In the traditional education system, the teacher transfers knowledge through lectures to the students. It is 
known as didactic model where the aim is to transfer information and knowledge from teacher to student. The teacher centric approach leaves the students to focus on memorizing facts rather than understanding the concepts at the practical level. In contrast to didactic teaching methodology there is dialectic model of teaching where the discussion method is used to understand and determine the merits of the topic. (Janssen, Skeen, Schutt, \& McMahon, 2008). The traditional way of teaching is now giving way to other pedagogies that rely on dialectic model of teaching. Group based learning is one of the forms of dialectic model of teaching.

It is a well-established and widely used collaborative student centric teaching methodology in education. Group based learning help students to apply concepts rather than simply learn about them. In group based learning students work together to achieve shared goals. (David W. Johnson, 1998). In Group Based Learning tasks are structured in such a way that each member in the group contributes to the completion of the tasks. The success depends upon the collaboration of the group members with each other rather than on individual efforts. In Group-Based-Learning it is assumed that learning takes place as members interact. (Kettunen, 2012).

\subsection{Team-Based-Learning}

However, for effective learning groups must be transformed into teams. The term Team-Based-Learning (TBL) was originally coined during the 1970 s by Larry Michaelsen of University of Oklahoma. (Michaelsen \& Sweet, 2008).

In order for groups to become team certain transformation must take place. First, a team must spend time interacting with one another, use resources and work on a challenging task together. Hence the group is committed together to work on the challenging task. The group members should also have the opportunity to comment on the performance of each individual and on the overall performance of the group. (Brame \& Biel, 2015). For convenience purpose the term Group Based Learning and Team Based Learning would be used interchangeably in the paper.

In TBL students do not merely cover contents but use course contents to solve problems. The students use problem solving skills to explore real world scenarios. Many studies have shown that TBL improves the students learning, engagement and improvement. (Utschig, 2019). Team based-learning is a teaching technique in which students work in teams and achieve a noticeably higher quality of learning than if they were learning individually.

The Team Based Learning is based on pedagogical principles and the constructivist learning theory. If the group solves a task that it was unable to solve beforehand than team based learning has taken place. Hence the groups were able to transform themselves into powerful learning teams. Cohesiveness and trust among group members make the foundation of effective team based learning. (Hrynchak \& Batty, 2012).

In Team Based Learning the instructor's primary role is to design and manage the overall instructional process. In Team-Based-Learning the teacher establishes the learning objectives and set the problems on which the students are going to work.

Benefits of TBL include ability to tackle tasks of higher complexity, a stronger consideration to develop diverse perspectives and developing a higher level of critical thinking.

For implementing TBL as a successful instructional strategy following characteristics of Team must be developed. The key point is to develop high level of cohesiveness and trust among team members without deviating from the course contents. (Mosher, 2013).

One of the most important factors that determines successful TBL is that the feedback should be given to members on regular basis. It provides improved learning, better classroom participation and enjoyable learning experience for students. Through GBL, students interact and learn from each other under the supervision of a teacher. Students are usually given a task to work on whilst the teacher goes around supporting and assessing them. (Johnson, Johnson, \& Smith, 1998).

There could be various reasons for assigning group-based projects. Sometime teachers want the group dynamics to be utilized rather than individual efforts and in some cases teachers cover the contents through group based learning rather than through lectures or given individual assignments. Whatever the reason for assigning group based learning it is critical to learn how to function in groups for organizational success in the practical field. Hence, teachers are required to make group based learning as part of their course outline so that students learn how to function within groups effectively. (Mannix \& Neale, 2005).

Monitoring group based learning requires as much planning as designing a group based project/assignment. Effective monitoring of the group based learning process is based on providing a constructive framework for 
group interaction, gathering information and giving feedback on group interactions, anticipating and preparing for potential problems. It is highly important to give feedback to group members and intervene them where necessary. (Al-Bashir, Kabir, \& Rahman, 2016).

Following characteristics have been identified for group based learning:

1. Learning is active

2. Teacher is more of a facilitator than a sage on the stage

3. Student must take responsibility for learning

\section{Students are required to reflect on their own learning process}

The group members have different level of knowledge, experience, skills, competence, interest, attitude toward work, often one member of the group dominates and imposes his/her point of view on other group members and there is an improper division of work among the group members. (Roskosa \& Rupniece, 2016).

However, just placing the students into groups will not enhance the collaboration. It is required to build incentive for collaboration within the group.

\subsubsection{Challenges in Group-Based-Learning}

Group-Based-Learning also represent challenges to both students and instructors. Sometimes students fail to pull their weights hence they are in the process of social loafing.

Further in the assessment of the group work individual contributions are not necessarily reflected in the marks resulting in unfair advantage to weaker students, subjective evaluation by the instructor, students may feel unfair in the allocation of tasks and marks, (Winchester-Seeto, 2002).

Following are some of the challenges that need to be overcome if Group-Based-Learning is to be a success.

1. Tracking individual student learning progress is extremely difficult.

2. Typically, group assessment marks are noted manually by the instructor.

3. Delayed feedback to students about their performance.

Further one of the major drawbacks of group based learning is the free-rider or hitchhiking effect. It exists when group members exert less effort when they see that their efforts are not required or could be dispended off for group success. Social loafing exists when the group members put less efforts as they see that without their efforts group could be successful. Then sucker effect exists when productive members withheld their efforts as they see that less contributing members are having a free-ride at their cost. (Frash, Kline, \& Stahura, 2008)

\section{ANALYSIS}

Currently software applications are unable to solve these issues. An innovative technology based app (Group Based Learning or GBL) has been developed that greatly improves student learning and reduces teacher's workload. The application automatically and in real-time provides the key data on $21^{\text {st }}$ century skills required for Group-Based-Learning. The GBL app eliminates the chances of free-riders in the group as the data with respect to the engagement and participation of each member of the group is captured in real time. The level of participation on various facets of Group Based Learning is recorded for each individual member of the group and instant feedback is available to the students. The collaborative nature of the Group Based learning is enhanced as the real time feedback is given to each individual member that motivates them to participate more effectively. This App is based on recently introduced quality assurance software ROFSET (Real-time Objective Feedback System for Effective Teaching).

Following are the key facets of ROFSET Framework.

a. Real-time: The data related to student learning is captured in real-time,

b. Non-intrusive: The software does not interferer or intrudes in the teaching.

c. Objective analysis: It eliminates the changes of prejudice and bias on part of the teacher as it is machine-based system thus it is not subjective.

d. Automated: Data capture and analysis of teaching and learning is done automatically hence the manual recoding of the student's learning is not required thus the system significantly reduces the workload of the 
teacher.

e. Artificial Intelligence (AI) engine: The embedded algorithms in the ROFSET Framework perform all the inferences on data. Al Engine generates reports and provides feedback to teachers on all Teaching and Learning Key Performance Indicators (TL-KPI).

The GBL app is a thin client that is used in GBL assignments and projects. GBL app has intelligence engine in the background continuously gathering data and analyzing data of all the TL-KPIs in real-time.

WE have tested GBL app in a class of Physics and our results show that using the GBL app, the students became much more responsive to learning. Also it allows the teacher to identify and support students who need more help (differentiated learning). In this work we present our findings on tracking students' skills in the following areas: Social, Communication, Analytics, Leadership and Effort (SCALE) for an introductory Physics class.

\section{RESULTS}

For assessing the Group Based Learning Technology (GBL app under ROFSET Framework) for Improving Student performance a group of 10 students was selected. The students were given GBL-assignments and their performance was assessed on five different aspects. These five aspects were Social Skills (through observation), Communication Skills (through audio recording), Analytics (Through Photos), Leadership skills (through task completion) and Efforts (Through observing Lateness/Punctuality). The results for the first lab experiment are given where GBL app was applied are given in Table 1. Here we can see that students score on average 3.1, 2.7, 1.7, 2.4 and 3.6 marks on the Social, Communication, Analytics, Leadership and Effort criteria. In Table 2 the results for subsequent lab experiments are given where we see from the result of lab 2 to lab 8 a gradual improvement has taken place in the scores of student on the above criteria.

For example, in Social skills an improvement of $32.3 \%$ has been recorded as we calculate the average result of the group from Lab 1 score of 3.1 has gone up to 4.1 . Similarly, communication skill has seen $66.7 \%$ increase, Analytical skill has seen $47.1 \%$ increase, Leadership skill has seen $75 \%$ increase and Effort of the group members has been increased by 33.3\%. Overall group performance has been increased by $48.9 \%$. The graphical representation of the data is given Fig 1, 2 and 3.

Table 1

\begin{tabular}{|c|c|c|c|c|c|c|}
\hline Student & Social (Obs) & Communication (audio) & Analytics (Photo) & Leadership (Task Compl) & Effort (Lateness) & Average \\
\hline 1 & $\begin{array}{r}3.0 \\
\end{array}$ & $\begin{array}{r}3.0 \\
\end{array}$ & \begin{tabular}{r|}
2.0 \\
\end{tabular} & $\begin{array}{r}3.0 \\
\end{array}$ & \begin{tabular}{|r|}
4.0 \\
\end{tabular} & 3.0 \\
\hline 2 & 4.0 & 4.0 & 1.0 & 3.0 & 5.0 & 3.4 \\
\hline 3 & 5.0 & 3.0 & 2.0 & 3.0 & 4.0 & 3.4 \\
\hline 4 & 2.0 & 3.0 & 2.0 & 2.0 & 3.0 & 2.4 \\
\hline 5 & 3.0 & 3.0 & 3.0 & 3.0 & 4.0 & 3.2 \\
\hline 6 & 3.0 & 2.0 & 2.0 & 3.0 & 3.0 & 2.6 \\
\hline 7 & 2.0 & 2.0 & 2.0 & 2.0 & 3.0 & 2.2 \\
\hline 8 & 2.0 & 2.0 & 1.0 & 2.0 & 4.0 & 2.2 \\
\hline 9 & 4.0 & 3.0 & 1.0 & 1.0 & 3.0 & 2.4 \\
\hline 10 & 3.0 & 2.0 & 1.0 & 2.0 & 3.0 & 2.2 \\
\hline Average & 3.1 & 2.7 & 1.7| & 2.4 & 3.6 & \\
\hline
\end{tabular}

Table 2

\begin{tabular}{|c|c|c|c|c|c|c|}
\hline & & Average $\mathrm{v}$ & s Lab & & & \\
\hline Lab & S & C & A & $\mathbf{L}$ & $\mathbf{E}$ & Average \\
\hline 1 & 3.1 & 2.7 & 1.7 & 2.4 & 3.6 & 2.7 \\
\hline 2 & 3.2 & 3.2 & 1.5 & 2.7 & 3.1 & 2.7 \\
\hline 3 & 3.0 & 3.5 & 1.7 & 2.9 & 3.3 & 2.9 \\
\hline 4 & 3.5 & 3.6 & 1.7 & 3.5 & 3.2 & 3.1 \\
\hline 5 & 3.4 & 3.8 & 1.6 & 3.7 & 3.5 & 3.2 \\
\hline 6 & 3.5 & 3.8 & 2.0 & 3.7 & 4.5 & 3.5 \\
\hline 7 & 3.7 & 3.7 & 2.1 & 3.9 & 5.0 & 3.7 \\
\hline 8 & 4.1 & 4.5 & 2.5 & 4.2 & 4.8 & 4.0 \\
\hline Average & 3.4 & 3.6 & 1.9 & 3.4 & 3.9 & \\
\hline Change \% & 32.3 & 66.7 & 47.1 & 75.0 & 33.3 & 48.9 \\
\hline
\end{tabular}


Fig. 1

Individual Student 'SCALE' Skills

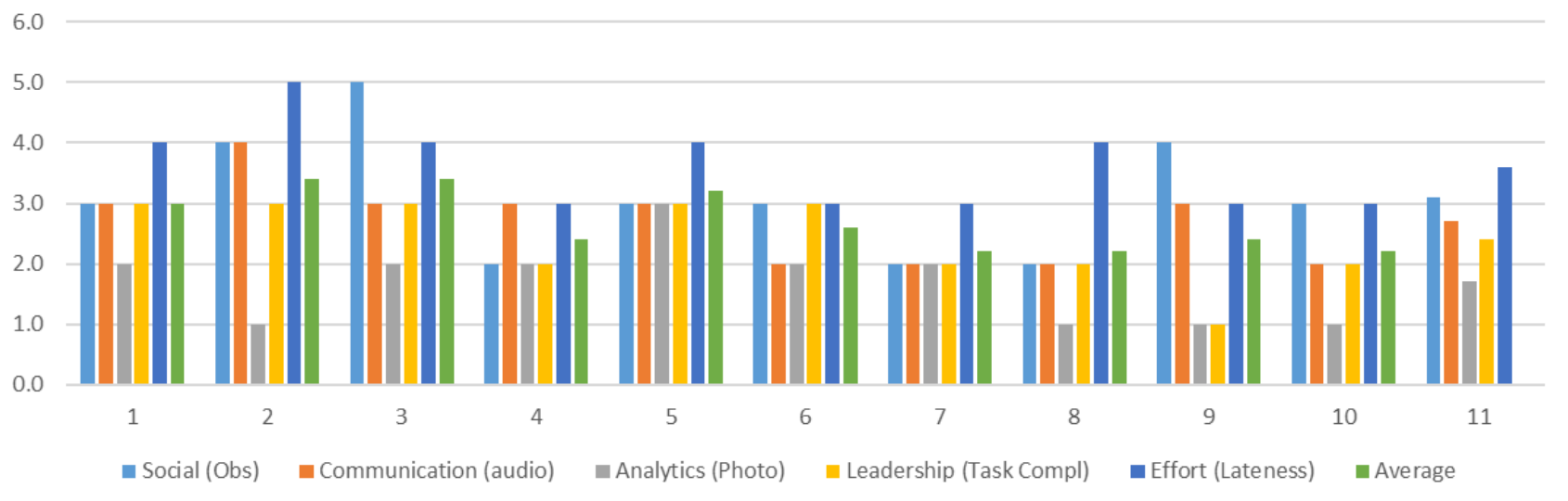

Fig. 2

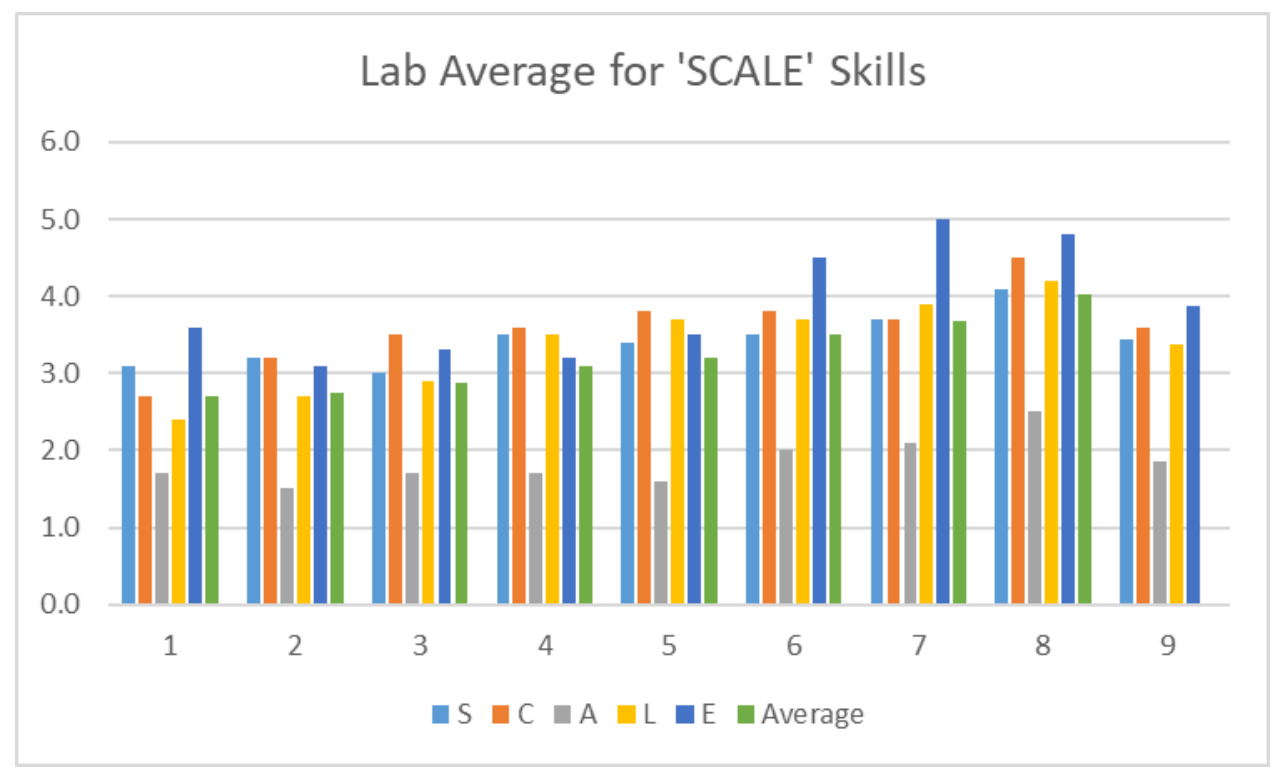

Fig. 3

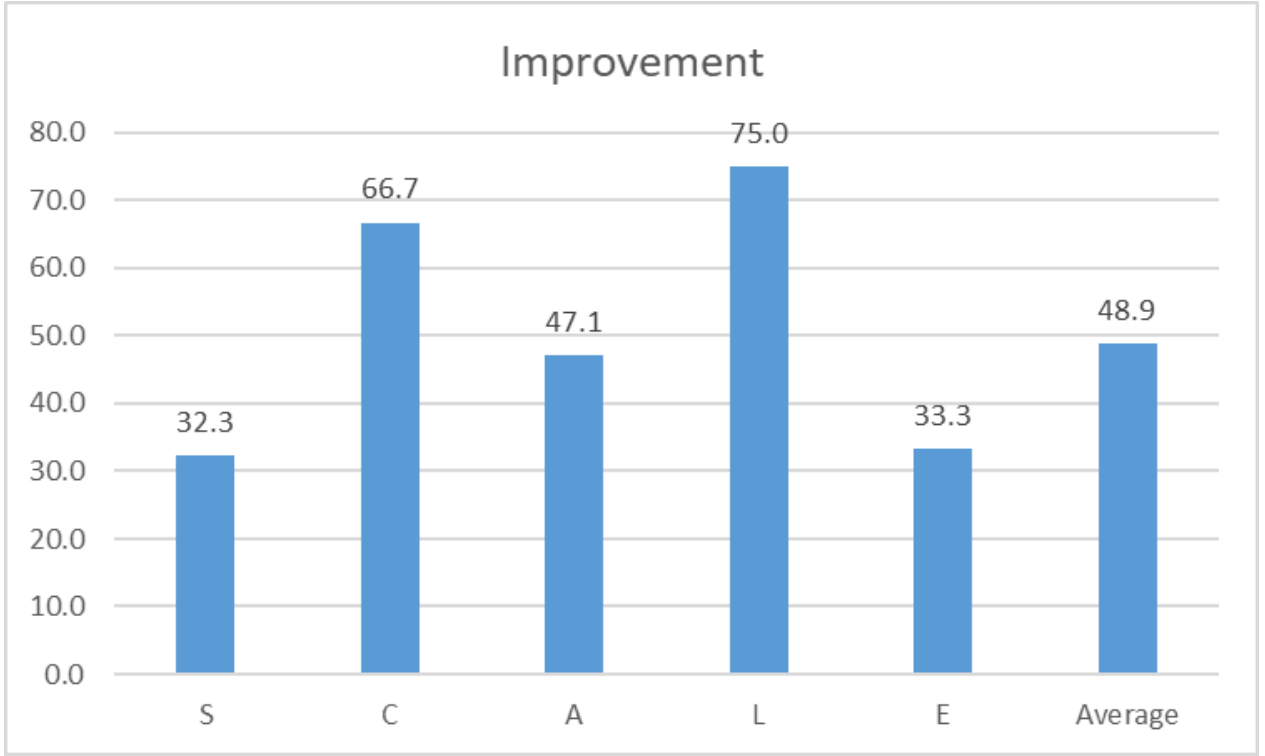




\section{CONCLUSION}

It is evident from the above experiment that the GBL app that works under the framework of ROFSET enhances the performance of the group. The reason for the improvement of group performance is attributed to real-time feedback that students and teacher get. The group dynamics also play an important role to motivate the group members to improve their performance as they get real=time, automated and objective assessment of their performance. Further individual efforts to score high also improve that overall performance of the group.

The free-rider syndrome is also eliminated as each member is aware of the efforts put by other group members. Peer pressure and the teacher intervention to guide the free-rider to perform better and put effort also results in improved performance of the group.

Through automated and real time feedback the teacher's burden is also reduced as the ROFSET system takes charge of recording the data about the student performance. Further the element of bias and prejudice that may be present in the assessment of the student performance under GBL has also been eliminated as the assessment of marks is now based on objective ROFSET framework.

\section{REFERENCE LIST}

Al-Bashir, M. M., Kabir, M. R., \& Rahman, I. (2016). The Value and Effectiveness of Feedback in Improving Students' Learning and Professionalizing Teaching in Higher Eductaion. Journal of Education and Practice, 7(16).

Brame, C., \& Biel, R. (2015). Group work: Using cooperative learning groups effectively. Retrieved December 21, 2019, from Center for Teaching: Vanderbilt University: https://cft.vanderbilt.edu/guidessub-pages/setting-up-and-facilitating-group-work-using-cooperative-learning-groups-effectively/

David W. Johnson, R. T. (1998). Cooperative Learning Returns To College What Evidence Is There That It Works? Change: The Magazine for Higher Learning , 27-35.

Frash, R. E., Kline, S., \& Stahura, J. M. (2008). Mitigating Social Loafing in Team-Based Learning. Journal of Teaching in Travel \& Tourism, 57-77.

Hrynchak, P., \& Batty, H. (2012). The educational theory basis of team-based learning theory. Medical Teacher, 796-801.

Janssen, H. F., Skeen, N. P., Schutt, R. C., \& McMahon, K. K. (2008). An Educational Rationale for the Use of Team-Based Learning : Didactic vs. Dialectic Teaching. In L. Michaelson, D. Parmelee, K. K. McMahon, \& R. E. Levine, Team BAsed Learning for Health Professions Education (pp. 75-84). Virginia: Sterling.

Johnson, D. W., Johnson, R. T., \& Smith, K. A. (1998). Cooperative Learning Return to College . Change.

Kettunen, J. (2012). Integrated Higher Education Management: Summary of Management Approaches. In Quality Assurance and Management.

Mannix, E., \& Neale, M. A. (2005). What Differences Make a Difference?: The Promise and Reality of Diverse Teams in Organizations. Psychological Science in Public Interest , 6 (2), 31-55.

Michaelsen, L., \& Sweet, M. (2008, June). Team-Based Learning . Thriving in Academe . Retrieved from Team Based Learning Collaborative.

Mosher, G. A. (2013). Formation and Development of Effective Student Teams to Facilitate Team Based Learning. 2013 ASEE North Mid Western Section Conference. Fargo, North Dakota: lowa State University.

Raja, R., \& Nagasubramani, P. C. (2018). Impact of modern technology in education. Journal of Applied and Advanced Research

Roskosa, A., \& Rupniece, D. (2016). Advantages and drawbacks of using group work in translator training. Procedia Social and Behavioral Sciences 231, 244-250.

Utschig, T. (2019). Team-Based-Learning. Retrieved 12 21, 2019, from Center for Excellence in Teaching 
and Learning: Kansas State University: https://cetl.kennesaw.edu/team-based-learning-tbl

Winchester-Seeto, T. (2002). Assessment of collaborative work - collaboration versus assessment. . Invited paper presented at the Annual Uniserve Science Symposium. Sydney: University of Sydney. 